\title{
A peek behind the curtain
}

\section{Kamali-Sadeghian' ${ }^{1}$ P. T. G Bot ${ }^{1} \cdot$ R. Tukkie ${ }^{1}$ H. J. Wellens ${ }^{2}$ • D. J. van Doorn}

Published online: 2 August 2018

(c) The Author(s) 2018

\section{Question}

A 67-year-old male was referred to the outpatient clinic of our hospital with crescendo angina pectoris since one month. He had been diagnosed with atrial fibrillation in a general practice three days earlier and treatment with metoprolol and apixaban was initiated. He was an otherwise healthy and active cyclist who smoked a cigar on occasion. There were no other risk factors for coronary artery disease. An echocardiogram performed five years ago because of persistent bradycardia, was normal.

Physical and laboratory examination on admission did not reveal any abnormalities. His initial troponin I level was
$11 \mathrm{ng} / \mathrm{l}$, with repeat troponin I concentration found at $14 \mathrm{ng} / \mathrm{l}$ (normal range $0-10 \mathrm{ng} / \mathrm{l}$ ). The resting electrocardiogram at presentation is shown in Figs. 1 and 2.

What is your diagnosis based on the electrocardiographic findings?

What would be your next step or treatment?

\section{Answer}

You will find the answer elsewhere in this issue.

Open Access This article is distributed under the terms of the Creative Commons Attribution 4.0 International License (http:// creativecommons.org/licenses/by/4.0/), which permits unrestricted use, distribution, and reproduction in any medium, provided you give appropriate credit to the original author(s) and the source, provide a link to the Creative Commons license, and indicate if changes were made.
M. Kamali-Sadeghian

mkamalisadeghian@spaarnegasthuis.nl

1 Department of Cardiology, Spaarne Gasthuis, Haarlem, The Netherlands

2 Department of Cardiology, Maastricht University Medical Center, Maastricht, The Netherlands 


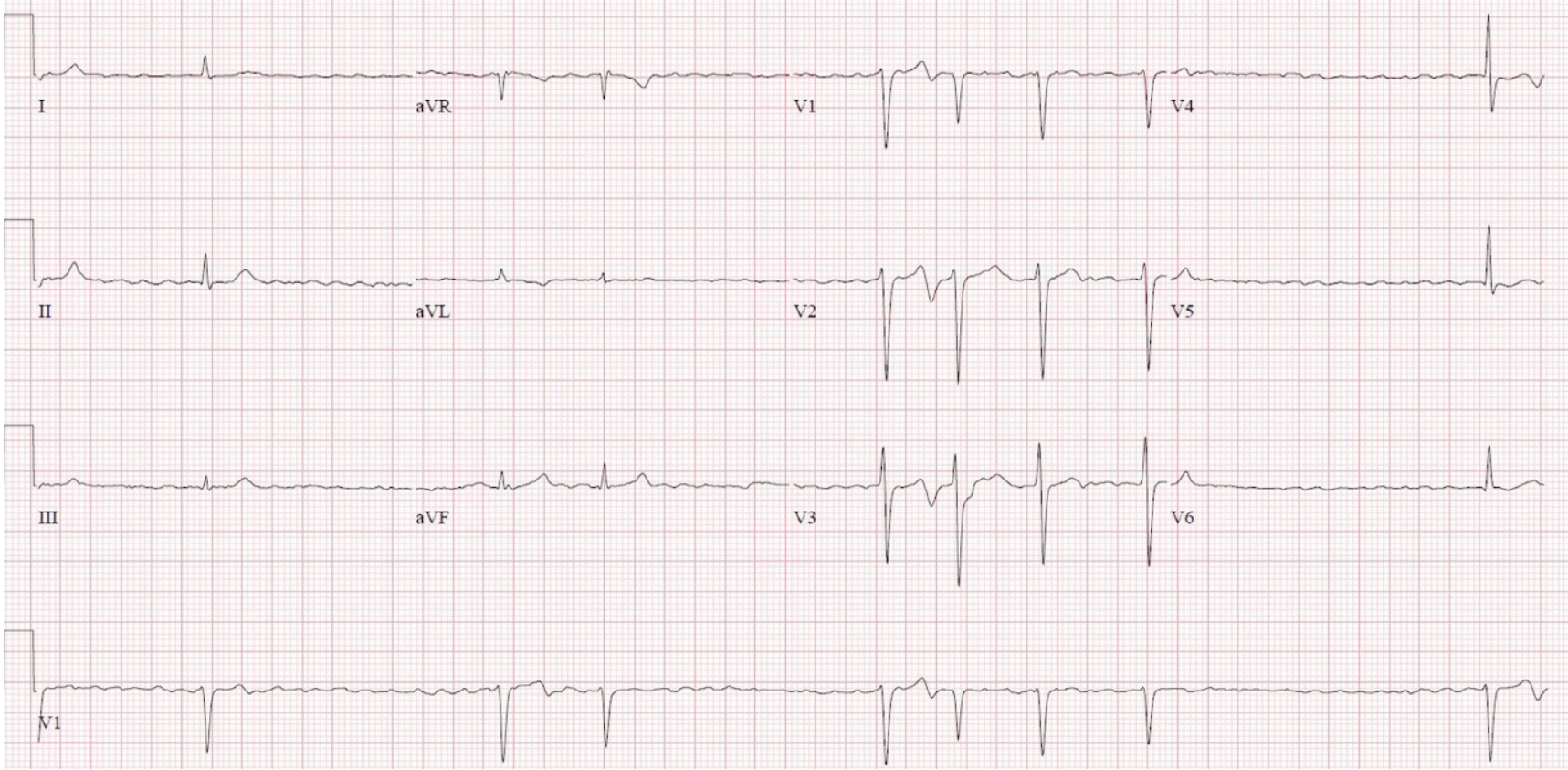

Fig. 1 Electrocardiogram on admission in an asymptomatic patient

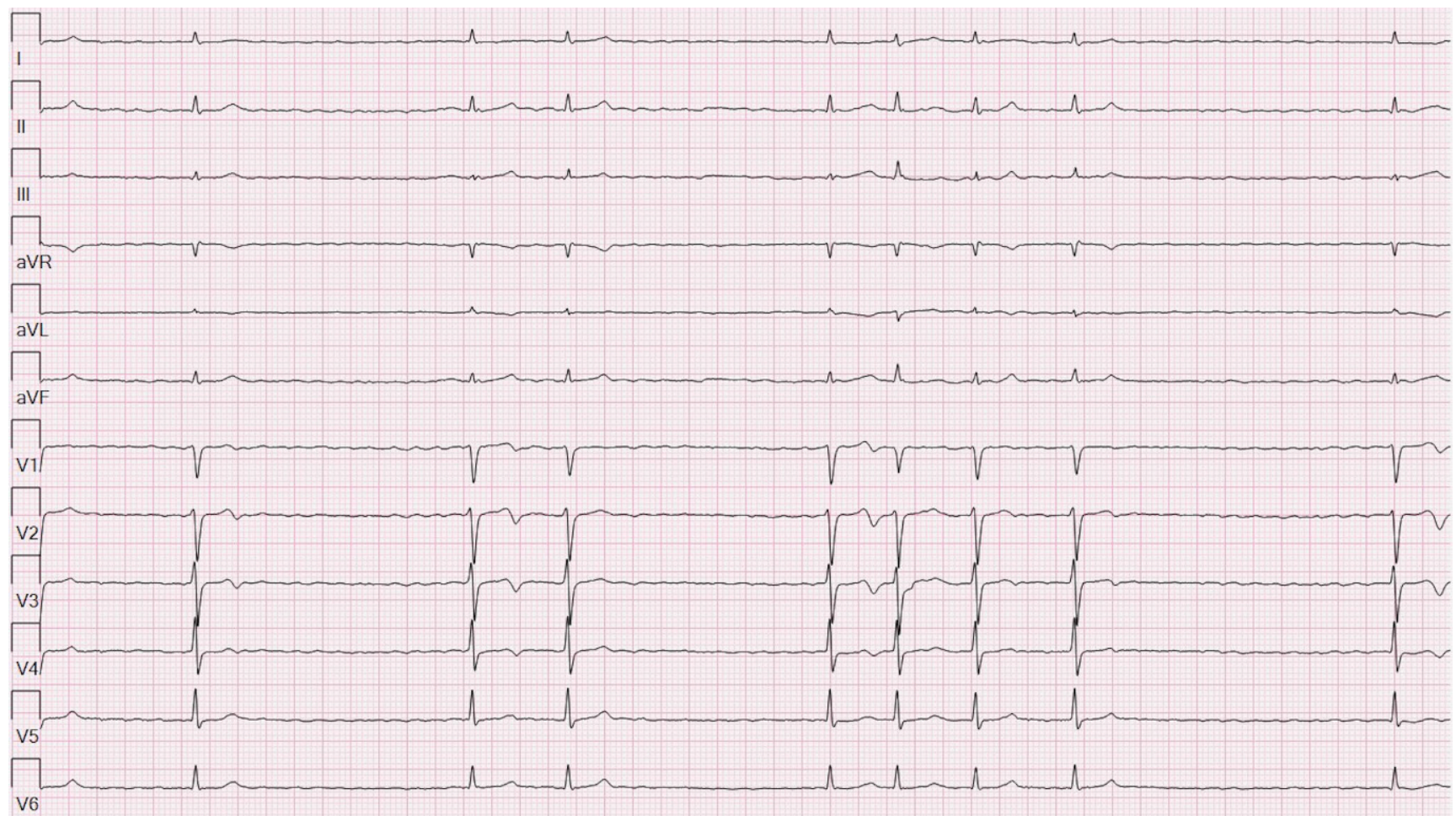

Fig. 2 The same electrocardiogram displayed in a 12-lead rhythm strip 